\section{Effects of Fertilizer Rate on Growth and Fruiting of Containerized Southern Highbush Blueberry}

\author{
Wendy L. Wilber and Jeffrey G. Williamson ${ }^{1}$ \\ Horticultural Sciences Department, University of Florida, P.O. Box 110690, \\ 2113 Fifield Hall, Hull Road, Gainesville, FL 32611-06900
}

Additional index words. Vaccinium, nitrogen, plant nutrition, pine bark

\begin{abstract}
The effects of fertilizer rate and composition on growth and fruiting of 'Misty' and 'Star' southern highbush blueberry were evaluated in a containerized production system using pine bark medium. Two fertilizer analyses $(12 \mathrm{~N}-1.8 \mathrm{P}-46.6 \mathrm{~K}$ and $12 \mathrm{~N}-$ 5.2P-9.9K) and three fertilizer rates were used. Plant growth and fruiting were unaffected by fertilizer analysis. Growth and fruit yield of 'Star' increased linearly with increasing fertilizer rate. For 'Misty', plant growth and yield were reduced at the highest fertilizer rate as a result of a high incidence of blueberry stem blight associated with that treatment. Flower bud density was highest for the 'Misty' plants receiving the high fertilizer rate and this may have resulted in excessive fruit set leading to stress-induced blueberry stem blight. Optimum fertilizer rates for young southern highbush blueberry plants grown in containerized pine bark systems appear to be cultivar-specific and similar to fertilizer requirements in soil culture.
\end{abstract}

Blueberry acreage has increased substantially in the southeastern United States during the past 5 years and further expansion is expected for the foreseeable future (National Agricultural Statistics Service, 2007; Strik and Yarborough, 2005; Williamson and Lyrene 2004b). Many new southern highbush blueberry (SHB) plantings in the southeastern United States are grown in pine bark beds that are 15 to $20 \mathrm{~cm}$ deep and of varying widths rather than in the underlying soil (Williamson et al., 2006; Williamson and Lyrene, 2005). Pine bark culture provides an ideal substrate for blueberry roots (Clark and Moore, 1991; Lyrene, 1990) and this practice allows for commercial blueberry production in areas with native soils that are poorly suited for blueberry production. Moreover, containerized blueberry production using pine bark as the growing medium has increased in the southeastern United States during the past 10 years, particularly in areas where the climate allows for early production but soils are not suitable for blueberry (personal observation). Blueberry production in greenhouses, plastic tunnels, and other protective culture systems may have potential for earlier, or extended, fruit harvest seasons (Ciordia and Diaz, 2006; Heiberg and Lunde, 2006; Ozeki and Tamada, 2006; Pliszka, 1996). Containerized plants are well suited to such temporary systems. General guidelines for blueberry fertilization are available from most Land Grant Universities (Krewer and Nesmith, 2006; Pritts and Hancock, 1992; Williamson et al., 2006; Williamson and Lyrene, 2005); however, little informa-

\footnotetext{
Received for publication 6 July 2007. Accepted for publication 1 Aug. 2007.

${ }^{1}$ To whom reprint requests should be addressed; e-mail jgrw@ufl.edu
}

tion is available for fertilization requirements in pine bark or containerized production systems. The objective of this study was to determine the effect of fertilizer rate and composition on growth and yield of two SHB blueberry cultivars grown in a containerized pine bark production system.

\section{Materials and Methods}

One-year-old 'Misty' and 'Star' SHB nursery plants were obtained from a north Florida nursery in April 1999, and potted in 30-cm diameter 19-L containers using smallnugget pine bark as the growing medium. Initial plant height and canopy width were measured. The plants were arranged in a randomized complete block design with seven replications and grown outdoors at the University of Florida greenhouse complex in Gainesville, FL. Plant spacing was $0.6 \mathrm{~m}$ in rows with $1 \mathrm{~m}$ between rows. The treatments consisted of two fertilizer analyses applied at three rates to two cultivars using a two-cultivar $\times$ two-analysis $\times$ three rate factorial arrangement of treatments. The two fertilizer analyses were: 1 ) a commercial blend of $12 \mathrm{~N}-1.8 \mathrm{P}-6.6 \mathrm{~K}$ (Blueberry Special; Seminole Marico, Ocala, FL); and 2) a $12 \mathrm{~N}-$ $5.2 \mathrm{P}-9.9 \mathrm{~K}$, which was blended by supplementing the $12 \mathrm{~N}-1.8 \mathrm{P}-6.6 \mathrm{~K}$ fertilizer with additional potassium sulfate and triple super phosphate to achieve a $12 \mathrm{~N}-5.2 \mathrm{P}-9.9 \mathrm{~K}$ analysis. The nitrogen was derived from $9.0 \%$ ammoniacal N, 0.04\% water-soluble organic $\mathrm{N}, 1.1 \%$ urea, and $1.5 \%$ water-insoluble organic N. Initial fertilizer rates were $3.5 \mathrm{~g}$, $7.0 \mathrm{~g}$, and $10.5 \mathrm{~g}$ of fertilizer per plant applied at 2-week intervals beginning in April 1999 and ending in Oct. 1999 (16 applications). Plants were repotted to $56-\mathrm{cm}$ diameter $95-\mathrm{L}$ containers in Dec. 1999. Fertilizer rates were increased by $50 \%$ (16 applications of $5.2 \mathrm{~g}$, $10.5 \mathrm{~g}$, and $15.8 \mathrm{~g}$, respectively) for the second and third growing seasons. Total annual $\mathrm{N}$ applied per plant was $6.7 \mathrm{~g}, 13.4 \mathrm{~g}$, and $20.2 \mathrm{~g}$ in 1999 and $10.5 \mathrm{~g}, 20.1 \mathrm{~g}$, and $30.0 \mathrm{~g}$ in 2000 and 2001. Plants were irrigated with $3.4 \mathrm{~L}$ of water per day from October through April and with $5.1 \mathrm{~L} /$ day during May through September using microirrigation emitters (Roberts, San Marcos, CA). Plant growth and fruit yield are reported for the second and third growing seasons.

Canopy volumes were determined before and after harvest during both years by measuring plant height and plant width parallel and perpendicular to the row. Plants were pruned in June 2000 after fruit harvest. Plant canopies were harvested at the end of the experiment in June 2001 and partitioned into primary canes, lower-order canes, and leaves. All tissues were dried at $70{ }^{\circ} \mathrm{C}$ to a constant weight and weighed.

Leaf retention was determined by weekly observations from December to February of each year. A subjective rating scale was used in which $10=$ complete leaf retention and $1=10 \%$ leaf retention. Leaf analyses for N, P, and $\mathrm{K}$ concentrations were conducted in Aug. 2000. Mature leaves located $\approx 10$ to $20 \mathrm{~cm}$ from shoot terminals were collected and dried for $5 \mathrm{~d}$ at $50{ }^{\circ} \mathrm{C}$ and ground. Percent nitrogen was determined by total Kjeldahl nitrogen (TKN), and percent phosphorus and potassium were determined by inductively-coupled argon plasma atomic emission spectroscopy.

Flower bud density was determined by counting the number of flower buds on the distal $13 \mathrm{~cm}$ of selected shoots in Dec. 2000 and 2001. Fruits were harvested and weighed at ₹3-d intervals from March until May in 2000 and from April until June in 2001. Data were analyzed by analysis of variance and mean separations were conducted using Duncan's multiple range test (SAS Institute, Cary, NC).

\section{Results and Discussion}

No interactions were observed between fertilizer analysis and fertilizer rate or between fertilizer analysis and cultivar. Furthermore, fertilizer analysis had no effect on any response variable other than leaf nutrient content. However, the cultivars responded differently to fertilizer rate for most response variables. Therefore, the effects of fertilizer rate (fertilizer analyses combined) are reported for each cultivar independently. For leaf nutrient content, the effects of fertilizer analysis and rate are shown for each cultivar.

Vegetative growth. Canopy volume for both cultivars increased linearly with fertilizer rate for the first 22 months of the experiment (through Feb. 2001) (Fig. 1). By Feb. 2001, 'Star' plants were larger than 'Misty' plants for each fertilizer rate. During 2001, 'Misty' plants receiving the high fertilizer rate developed a high incidence of blueberry stem blight (Botryosphaeria dothidea). By July, 2001, six of the 14 'Misty' plants receiving the high fertilizer rate were severely infected with blueberry stem blight. 




Fig. 1. Effect of fertilizer rate on canopy volumes of 'Misty' and 'Star' southern highbush blueberry.

The high incidence of blueberry stem blight resulted in a reduction in mean canopy volume during 2001 for 'Misty' plants receiving the high fertilizer rate. The incidence of blueberry stem blight was low or nonexistent for all other fertilizer rate/cultivar combinations. Trends for canopy dry weights were similar to canopy volume (Fig. 2). For 'Star', canopy dry weight increased linearly with increasing fertilizer rate. The components of canopy dry weight (leaves, primary canes, and lower-order canes) also increased linearly as fertilizer rate increased. For 'Misty', no relationships between fertilizer rate and canopy dry weight (or its component parts) were found, probably because of the stunted growth of stem blight-infected plants at the highest fertilizer rate. The one exception was leaf dry weights of 'Misty', which tended to increase linearly as fertilizer rate decreased.

Significant linear relationships were usually found between fertilizer rate and leaf

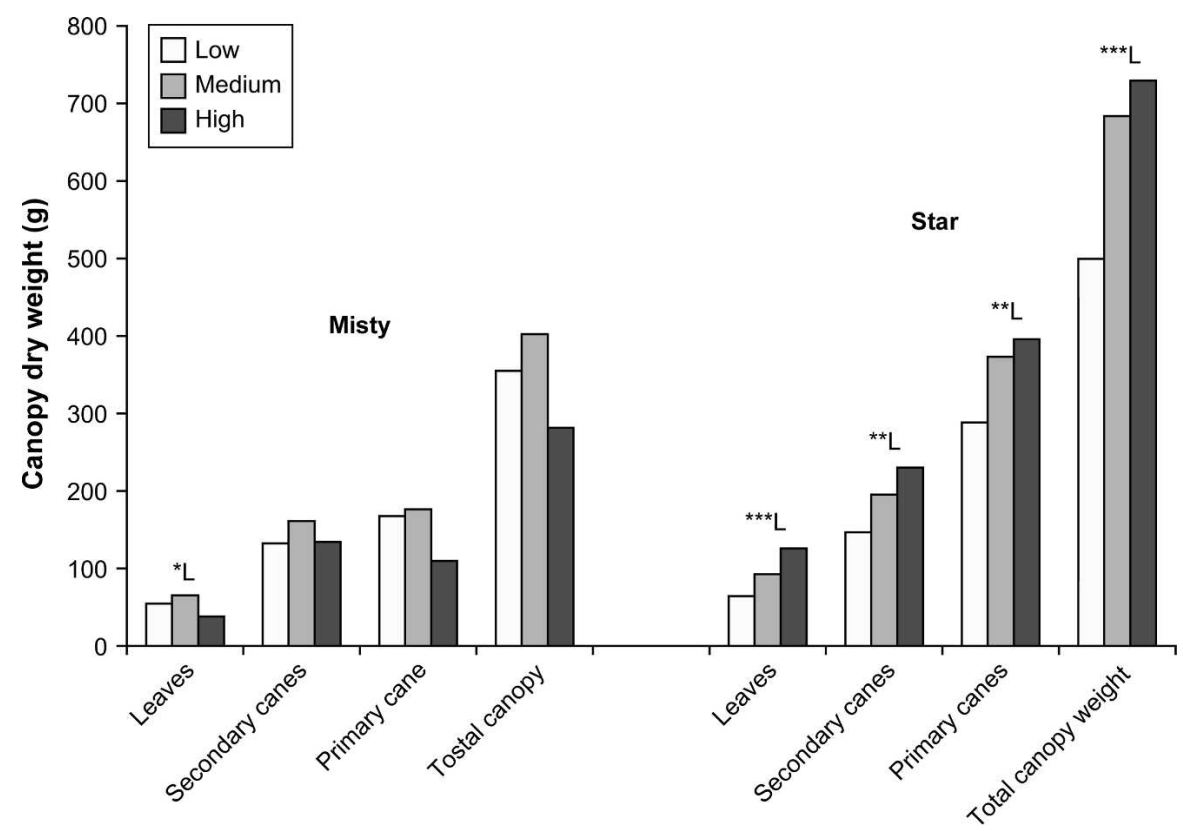

Fig. 2. Effect of fertilizer rate on canopy dry weights of 'Misty' and 'Star' southern highbush blueberry.
Reproductive growth. In 2001, a significant positive linear relationship was found between fertilizer rate and flower bud density (flower buds per centimeter of shoot length) for 'Misty' (data not shown). Flower bud density was much lower for 'Star' than for 'Misty' during both years and no relationship between fertilizer rate and flower bud density was observed for 'Star'.

Fertilizer rate did not affect total yield of 'Misty' plants during 2000; however, more fruit ripened earlier for the medium and high fertilizer rates than for the low rate (Fig. 3). Over twice as much fruit was harvested from the plants receiving the high and medium fertilizer rates as was harvested from the low fertilizer rate plants during the 24 Mar. to 21 Apr. period. During the second year, the medium fertilizer rate resulted in the highest fruit yield for 'Misty'. In Contrast to 'Misty', 'Star' fruit yield and ripening date were unaffected by fertilizer rate during 2000 (Fig. 3). However, during 2001, total fruit yield increased linearly with fertilizer rate, similar to that observed for canopy volume.

In all cases, fruit yield followed trends that were similar to canopy volume and canopy dry weight. For 'Star', no fertilizer rate effects were observed for these response variables during the first year. However, during 2001, fruit yield, canopy volume, and canopy dry weight increased linearly as fertilizer rate increased. These responses, and leaf analysis, suggest that the highest fertilizer rate did not exceed what was needed for maximum yield of 'Star' under these conditions. In this study, fruit yields of containerized 'Star' plants were similar to what would be expected from plants of the same age grown in field pine bark culture. In 2000 , canopy size and fruit yield were similar for both cultivars. However, by 2001, growth and yield were less for 'Misty' than for 'Star'. Contrary to 'Star', 'Misty' growth and yield were greatest for the medium fertilizer rate. In this case, the highest fertilizer rate resulted in reduced canopy size and weight and reduced fruit yield. Reduced plant size and fruit yield from the highest fertilizer rate appeared to be related to a high incidence of blueberry stem blight, which only occurred in that treatment. Blueberry stem blight is often a stress-induced disease and 'Misty' is highly susceptible to this disease (Williamson and Lyrene, 2004a). Excessive fruit set is a common cause of blueberry stem blight in 'Misty'. During 2001, 'Misty' plants that were affected by stem blight also had the highest flower bud densities. Flower bud density of 'Misty' was increased by $\approx 20 \%$ for the high fertilizer treatment compared with the medium treatment and by $\approx 50 \%$ over the low fertilizer rate. However, these differences were not reflected in fruit yield because stem blight killed fruiting canes during the fruit development period thereby lowering fruit yield.

Fertilizer requirements for young SHB plants grown in a containerized pine bark system appear to be similar to fertilizer requirements in soil-based production systems 


\begin{tabular}{|c|c|c|c|c|c|c|c|c|c|c|c|c|}
\hline \multirow[b]{3}{*}{ Fertilizer rate } & \multicolumn{6}{|c|}{ Yr 1} & \multicolumn{6}{|c|}{ Yr 2} \\
\hline & \multicolumn{2}{|c|}{15 Dec. 1999} & \multicolumn{2}{|c|}{5 Jan. 2000} & \multicolumn{2}{|c|}{4 Feb. 2000} & \multicolumn{2}{|c|}{5 Dec. 2000} & \multicolumn{2}{|c|}{5 Jan. 2001} & \multicolumn{2}{|c|}{10 Feb. 2001} \\
\hline & Misty & Star & Misty & $\overline{\text { Star }}$ & Misty & $\overline{\text { Star }}$ & 'Misty' & 'Star' & 'Misty' & 'Star' & 'Misty' & 'Star' \\
\hline Low & 90 & 82 & 78 & 66 & 53 & 24 & 95 & 86 & 86 & 53 & 57 & 10 \\
\hline Medium & 94 & 82 & 86 & 66 & 76 & 31 & 98 & 92 & 96 & 67 & 86 & 16 \\
\hline High & 95 & 91 & 87 & 71 & 79 & 38 & 98 & 96 & 93 & 78 & 87 & 30 \\
\hline \multicolumn{13}{|l|}{ Significance } \\
\hline Linear & $*$ & $* *$ & $* * *$ & NS & $* * *$ & $*$ & NS & $* * *$ & $* *$ & $* * *$ & $*$ & $*$ \\
\hline Quadratic & NS & NS & NS & NS & $* *$ & $*$ & $*$ & NS & $* *$ & NS & $*$ & NS \\
\hline
\end{tabular}

Ns,****,****Nonsignificant, or significant at $P \leq 0.05,0.01$, or 0.001 , respectively.

Table 2. Effect of fertilizer treatments on leaf nutrient concentration (\% dry weight) of Misty and Star southern highbush blueberry.

\begin{tabular}{|c|c|c|c|c|c|c|}
\hline \multirow[b]{2}{*}{ Fertilizer rate } & \multicolumn{3}{|c|}{ Star } & \multicolumn{3}{|c|}{ Misty } \\
\hline & $\mathrm{N}$ & $\mathrm{P}$ & $\mathrm{K}$ & $\mathrm{N}$ & $\mathrm{P}$ & $\mathrm{K}$ \\
\hline Low & 1.61 & 0.082 & 0.889 & 1.52 & 0.07 & 0.821 \\
\hline Medium & 1.66 & 0.085 & 0.945 & 1.78 & 0.081 & 0.737 \\
\hline High & 1.84 & 0.093 & 1.01 & 1.88 & 0.089 & 0.749 \\
\hline Linear & $* * *$ & $* * *$ & NS & $* * *$ & $* * *$ & NS \\
\hline \multicolumn{7}{|l|}{ Fertilizer } \\
\hline $12 \mathrm{~N}-5.2 \mathrm{P} 12-9.9 \mathrm{~K}$ & 1.17 & 0.089 & 1.01 & 1.73 & 0.082 & 0.38 \\
\hline $12 \mathrm{~N}-1.8 \mathrm{P}-6.6 \mathrm{~K}$ & 1.69 & 0.084 & 0.88 & 1.73 & 0.078 & 0.39 \\
\hline Significance & NS & $*$ & $* *$ & NS & NS & NS \\
\hline
\end{tabular}

Ns,,$* * * * * * *$ Nonsignificant, or significant at $P<0.05,0.01$, or 0.001 , respectively.

Fertilizer rates: low $=96 \mathrm{lbs} /$ acre, medium $=192 \mathrm{lbs} /$ acre, high $=288 \mathrm{lbs} /$ acre.
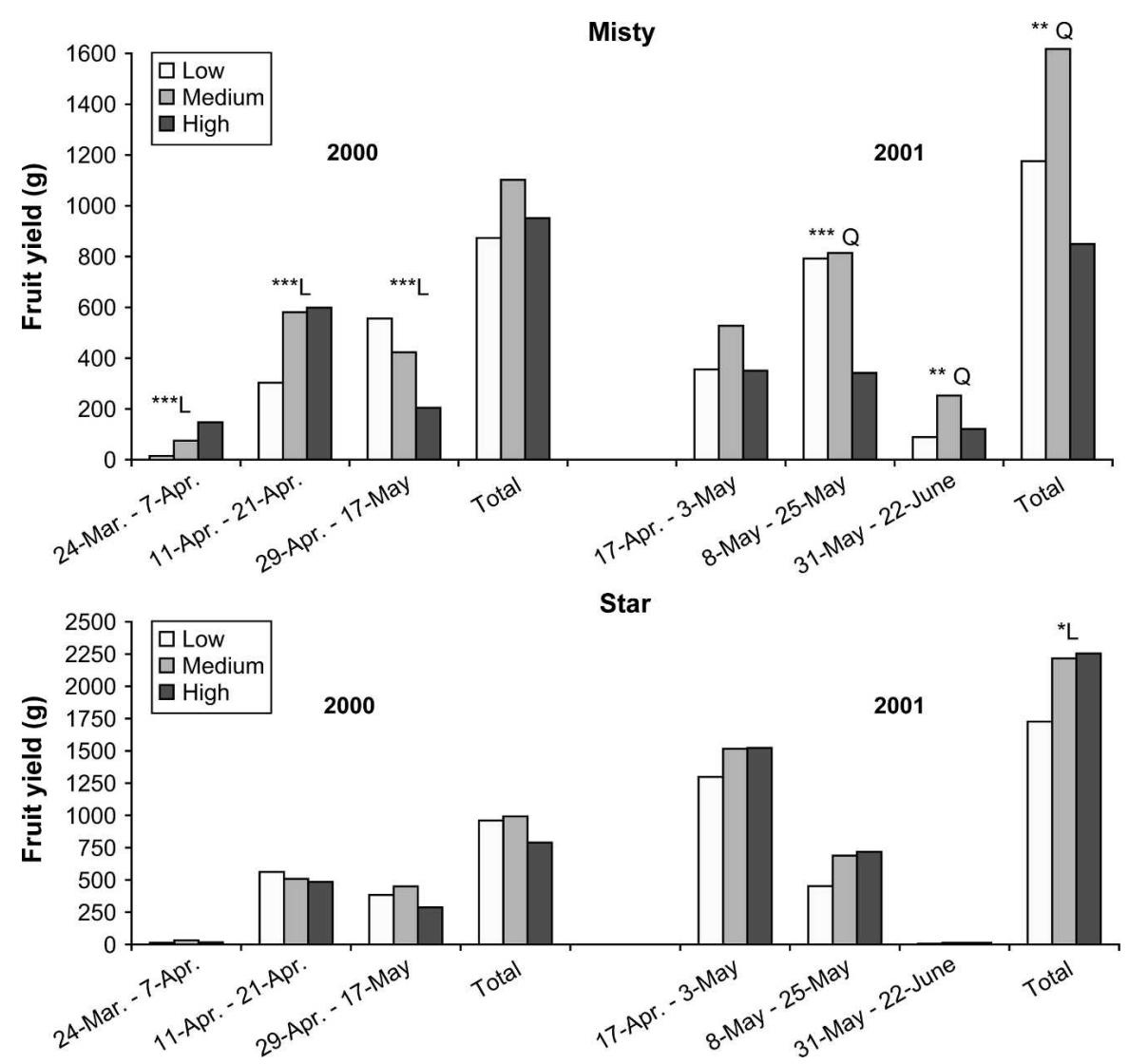

Fig. 3. Effect of fertilizer rate on fruit yield of 'Misty' and 'Star' southern highbush blueberry.

where maximum growth of young plants is desired (Krewer and NeSmith, 2006). Large increases in growth and fruit yield were observed for both cultivars as fertilizer rates increased from low to medium. However, optimum fertilizer rates for young SHB blueberry appear to be cultivar specific. Plant study, but the incidence of blueberry stem blight was high for 'Misty' but not for 'Star' in the high fertilizer treatment. Although more work is needed to clarify fertilizer requirements for container-grown SHB blueberry under a variety of conditions and cultural practices this study suggests that total annual fertilizer demand may be similar to that reported for soil based systems.

\section{Literature Cited}

Ciordia, M. and M.B. Diaz. 2006. Off-season production of southern highbush blueberries in the north of Spain. Acta Hort. 715:317-322.

Clark, J.R. and J.N. Moore. 1991. Southern highbush blueberry response to mulch. HortTechnology 1:52-54.

Eck, P. 1988. Blueberry science. Rutgers University Press, New Brunswick, NJ.

Heiberg, N. and R. Lunde. 2006. Effect of growth media on highbush blueberries grown in pots. Acta Hort. 715:219-223.

Krewer, G. and D.S. Nesmith. 2006. Blueberry fertilization in soil. The Southern Small Fruit Consortium. 29 June 2007. <www.smallfruits. org $>$.

Lyrene, P. 1990. Low chill highbush blueberries fruit varieties. Fruit Varieties J. 44:82-86.

National Agricultural Statistics Service (NASS). U.S. Department of Agriculture. Noncitrus fruits and nuts preliminary summary, Jan. 2007. Mar. 2007. <www.nass.usda.gov>.

Ozeki, M. and T. Tamada. 2006. The potentials of forcing of southern highbush blueberry in Japan. Acta Hort. 715:241-246.

Pliszka, K. 1996. Overview on Vaccinium production Europe. Acta Hort. 446:49-52.

Pritts, M.P. and J.F. Hancock. 1992. Highbush blueberry production guide. Pub. NRAES-55. Northeast Regional Agricultural Engineering Service. Cooperative Extension Service, Ithaca, NY.

Strik, B.C. and D. Yarborough. 2005. Blueberry production trends in North America, 1992 to 2003, and predictions for growth. HortTechnology 15:391-398.

Williamson, J.G., G. Krewer, G. Pavlis, and C.M. Mainland. 2006. Blueberry soil management, nutrition and irrigation, p. 60-74. In: P. Eck, N.F. Childers, and P.M. Lyrene (eds.). Blueberries: For growers, gardeners, promoters. Dr. Norman F. Childers Publications, Gainesville, FL.

Williamson, J.G. and P.M. Lyrene. 2004a. Blueberry varieties for Florida. University of Florida, Gainesville, FL. 29 June 2007. <http://edis. ifas.ufl.edu>.

Williamson, J.G. and P.M. Lyrene. 2004b. The Florida blueberry industry: A decade of growth. Proc. Fla. State Hort. Soc. 117:234-235.

Williamson, J.G. and P.M. Lyrene. 2005. Commercial blueberry production in Florida. University of Florida, Gainesville, FL. 29 June 2007. <http:// edis.ifas.ufl.edu $>$. 